\title{
SOME EXPERIMENTS ON THE SYMBIOTIC ASSOCIATION BETWEEN SEA ANEMONE AND AMPHIPRION
}

\author{
$\operatorname{AUTHOR}(\mathrm{S}):$
}

Fukui, Yoko

\section{CITATION:}

Fukui, Yoko. SOME EXPERIMENTS ON THE SYMBIOTIC ASSOCIATION BETWEEN SEA ANEMONE AND AMPHIPRION. PUBLICATIONS OF THE SETO MARINE BIOLOGICAL LABORATORY 1973, 20: 419-430

\section{ISSUE DATE:}

1973-12-19

URL:

http://hdl.handle.net/2433/175767

RIGHT: 


\title{
SOME EXPERIMENTS ON THE SYMBIOTIC ASSOCIATION BETWEEN SEA ANEMONE AND AMPHIPRION
}

\author{
Yoko FUKUI ${ }^{11}$ \\ Department of Biology, Ochanomizu University, Tokyo \\ and Tateyama Marine Laboratory, Tateyama, Chiba Prefecture
}

With 7 Text-figures

\begin{abstract}
The well-known story of close partnership between giant sea anemone and anemone fish was first taken up in experimental analysis by DEVENPORT in 1958, who was then followed by some other experimenters in east and west.

The general outcome from these studies seems to consist in that a process of 'accomodation' is necessary in one or both of the partners for the association to be established between them. The results of some experiments by the present author with Parasicyonis and Amphiprion (xanthurus etc.), however, have suggested a situation contrary to this. The fish behaves usually very cautious indeed in its first approach to the anemone and starts back repeatedly from the latter as if it has actually been stung by the tentacles, but microscopical examination of its scales always fails to show evidence of cnida discharge. 'Protective substance', if any, must be pre-existent rather than a product of accomodation. The apparent situation that the fish has no capacity of distinction between a proper partner species and a wrong one may be associated with this habit of cautious testing.

On the other hand, a sign of favorable state of relaxation and tranquilization in the part of anemone is observed to set in when this has been brought into association with an Amphiprion. Evidence has been found to indicate that this also is an immediate physiological effect of the contact which takes place without requiring a period of accomodation or adaptation.
\end{abstract}

The close symbiotic partnership between the anemone fish and the giant anemone is now too much reputed. The present-day industrialization of popular aquarium fish hobby has rendered this secret natural history of tropical coral reeves observable comfortably in our parlours back in northern civilization. It is indeed enjoyable to watch the scenes of beautiful partnership and to make rumors about the affair in anthropomorphic ways, but it is not necessarily an easy task to analyze the mechanism of establishment and maintenance of this social relationship in terms of behavioral physiology.

DAVENPORT (with cooperation of NORRIS) was among the first to take up this subject into controlled experimental analysis (DAVENPORT and NorRIS, 1958). He, in the course of serial studies on marine symbiosis, had been led to have a particular interest in cases of symbiosis with a cnidarian host, for the latter was usually a

1) Present address: Department of Biology, Tokyo Women's Medical College, Tokyo. 
dangerous friend because of its stinging capsules (DAVENPORT, 1966). Protection from stinging should have constituted a prerequisite for any symbiosis with a cnidarian.

DAVENPORT and NORRIS gave a detailed description of the behavior of both animals in the process of 'acclimation' of the fish to the host anemone, in which the fish approached the host first with much cautiousness. This cautious approach had already been emphasized by earlier observers such as GOHAR (1948) and VERWEY (1930). Another series of observations made by DAVENPORT and NORRIS was on the stinging by the tentacle nematocysts of the anemone. They showed effectiveness of the mucus from the fish's skin in suppressing the nematocyst discharge from the tentacles. They suggested that the hypothetical protective substance in the skin was developed or at least strengthened somehow during the behavioral process of 'acclimation', though the stinging tests were not specified in their description as having been done using exclusively those skin materials that were taken from acclimated fish. This suggestion was then supported by their followers, particularly MARISCAL (1969, 1970a, 1970b, 1970c), who tried to present extensive evidence for the development of protective substance in the fish's skin in the course of 'acclimation'. This was the case also in Schlichter (1968), who, however, tended to regard the protective substance as being simply transferred from the anemone to the fish body surface.

There is another school of recent authors, who would put the weight rather in changes of reactivity on the part of anemone. BLösCH $(1961,1965)$, for example, emphasized sensory adaptation of anemone's tentacles to the tactile stimuli given by

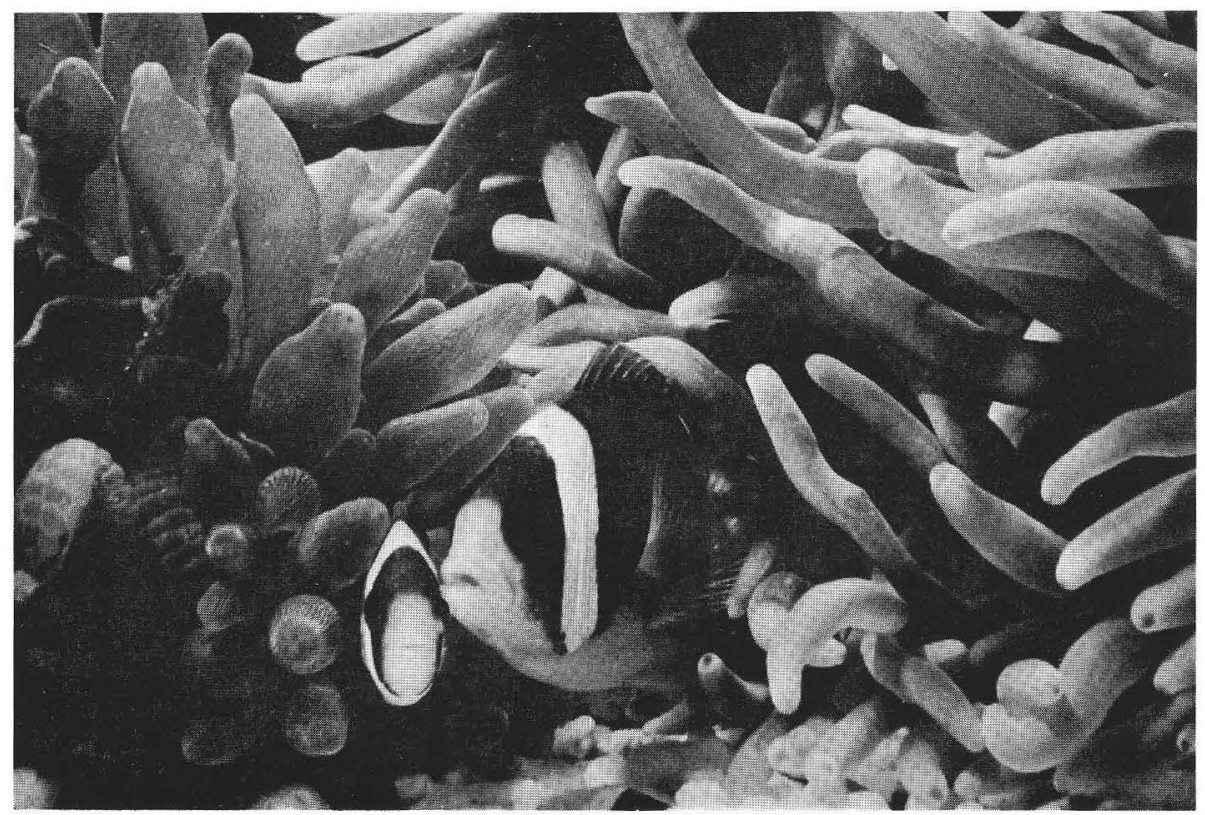

Fig. 1. The anemone Parasicyonis and partner Amphiprion. Photographed in laboratory aquarium. 
the fish. However, they are in agreement with the former group of authors in that a time course of acclimation (or adaptation) is assumed to be necessary for the protection of fish from stinging to be established.

It has been the aim of the present study to be presented below to re-examine these points experimentally. The giant anemones used in experiments, Parasicyonis actinostoloides, were collected from several localities on Cape Boso and Izu Peninsula. Stoichactis, which was the material used by DAVENPORT has been unavailable. Anemone fish, Amphiprion xanthurus, A. sebae and A. percula were bought from a wholesale dealer in Tokyo, who imported them from Okinawa and Manila. They were kept in laboratory aquaria and caution was paid in ensuring their separation from the anemone prior to experimentation (Fig. 1).

\section{Experimental Results}

The Process of Establishment of Association between the Partners:

The development of strength of bond after an anemone fish was placed in the same aquarium as an anemone was recorded by representing the strength of bond with percentage frequency of occurrence of the fish in the same section occupied by the anemone in a hexasected aquarium on each day after the encounter (Fig. 2). Namely, the small rectangular glass aquarium $(20 \mathrm{~cm} \times 35 \mathrm{~cm})$ was divided into six floor sections of equal area aligned in two rows of three, and the location of the fish was recorded

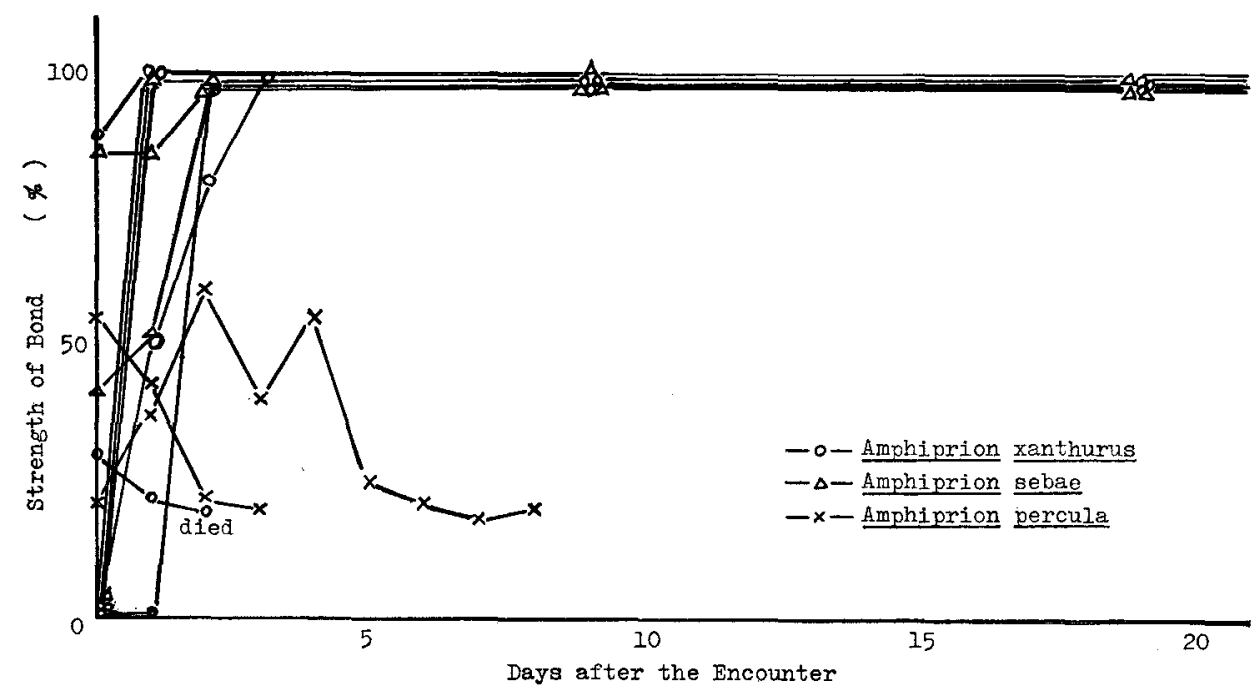

Fig. 2. The time course of establishment of association between three species of Amphiprion and Parasycyonis actinostoloides. Strength of bond is represented by percentage frequency of occurrence of the fish in the same section occupied by the anemone of the hexasected aquarium. The individual observations were made at intervals of $5 \mathrm{~min}$. for a certain period of time on each day. 
at intervals on each day. Besides, with $A$. sebae, a continuous recording of approaching behavior was taken for the first two hours of encounter with the anemone (Fig. 3). In this recording, the closeness to the anemone was represented by the actual distance between the two animals from time to time. The recognition by the fish of the anemone as an object to be tested took place apparently at the first moment of encounter, and a series of tests performed by the present author indicated that the sensory channel for this recognition was visual one, in accordance with the results obtained by BLöscH (1965).

As to the time course of establishment of association, there is a marked contrast between Amphiprion xanthurus and A. sebae, on one hand, and A. percula, on the other. The result indicates a specifically strong bond attained by the two first species of Amphiprion with the present species of anemone, while $A$. percula, the material used by DAvENPORT, showed a rather suspended attraction by this anemone. This is in agreement with BLöscH's results obtained from his trials of variety of combinations of partner species (BLösch, 1965). In the case of Amphiprion xanthurus and A. sebae, the changes observed in behavior of both partners during the process of association were essentially the same as has been reported by earlier authors, including DAVENPORT and NORRIS. 'Surprise' or 'pain' response of the fish on the first contacts with anemone was common also in the present cases. Only missing in the present materials was the phenomenon of tentacle clinging reported by some previous authors.

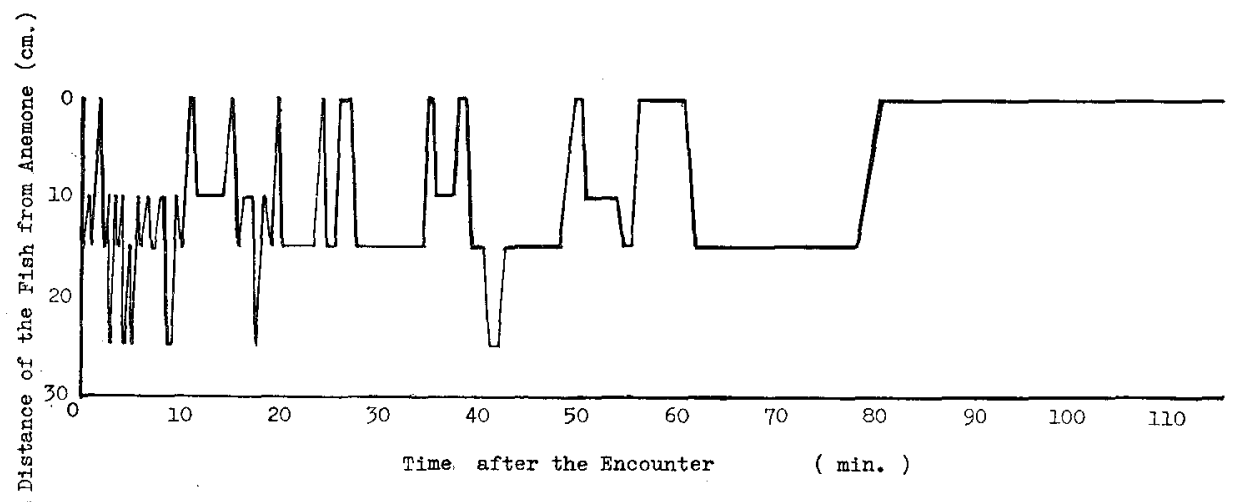

Fig. 3. The closeness of Amphiprion sevae to its host Parasycyonis in the time course of "acclimation". The closeness was measured by distance from center to center of the sections of the hexasected aquarium, in which the animals were located at that time.

The difference in associative behavior between Amphiprion percula versus $A$. xanthurus - A. sebae is to be seen also in Table 1 , which records the statistical frequency of the fishes (including non-symbiotic species used as controls) to stay close to the anemone host (as well as to a control inanimate object) for the first three days after the encounter.

All these results reconfirm more or less the 'cautious approach' of the fish at first 
Table 1. Average frequency (in percentage) for the first three days of the fish to stay in the same section of the hexasected aquarium as the anemone as well as the control object (a stone). All the five other sections were left vacant.: the figures in parentheses indicate number of experiments.

\begin{tabular}{|c|c|c|c|c|c|c|}
\hline \multirow{2}{*}{$\begin{array}{l}\text { Average closeness } \\
\text { in } \%\end{array}$} & \multicolumn{3}{|c|}{ Amphiprion } & \multicolumn{3}{|c|}{ non-Amphiprion } \\
\hline & A. percula & A. sebae & A. xanthurus & $\begin{array}{r}\text { Pomacentrus } \\
\text { coelestis }\end{array}$ & $\begin{array}{l}\text { Chasmichthys } \\
\text { dolichognatus }\end{array}$ & $\begin{array}{l}\text { modestus } \\
\text { Navodon }\end{array}$ \\
\hline $\begin{array}{l}\text { To } \\
\text { Parasicyonis }\end{array}$ & $40(1)$ & $80(3)$ & $82(2)$ & $1(2)$ & $2(1)$ & $1(1)$ \\
\hline $\begin{array}{l}\text { To } \\
\text { the control object }\end{array}$ & $33(1)$ & $50(1)$ & $20(1)$ & - & - & - \\
\hline
\end{tabular}

encounter as reported by the previous authors. Such an approach lead eventually to a close bond in the case of $A$. xanthurus and $A$. sebae, while it has failed for some unknown reason to attain a close bond in the case of $A$. percula. A noteworthy finding here, however, was that, as will be shown in the following section, this slow process of association could be accelerated by pushing close the hesitating fish ( $A$. xanthurus and $A$. sebae) forcibly on the anemone's tentacles with a dipnet or something like that. The fish was not only free from stinging even on such a forced contact, but attained almost at once to the final state of solid bond.

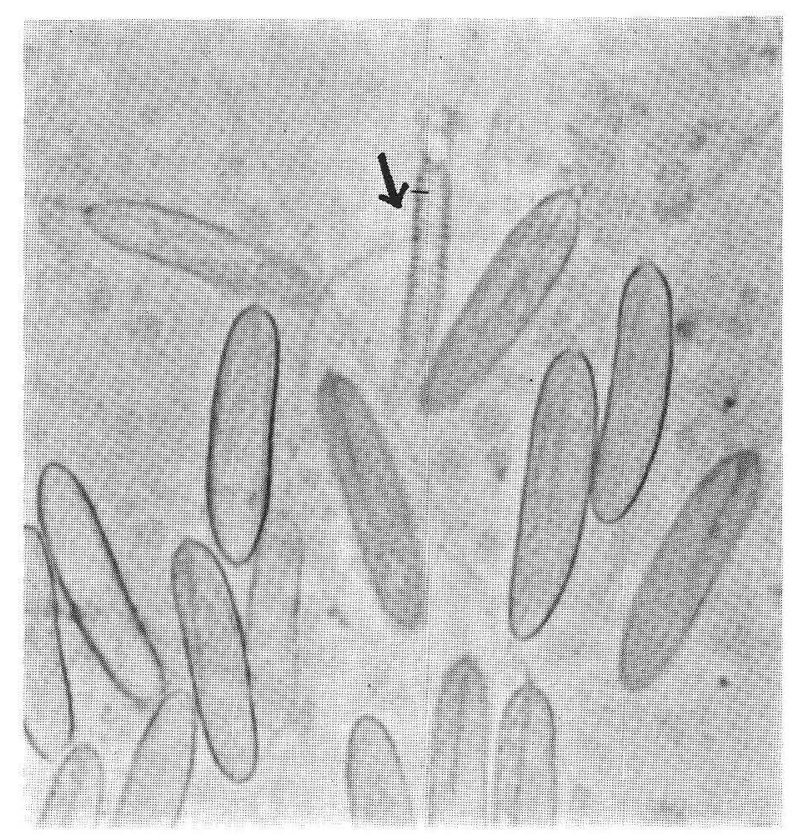

Fig. 4. Nematocysts and spirocyst in the tentacle of Parasicyonis (Arrow indicates a spirocyst.). 


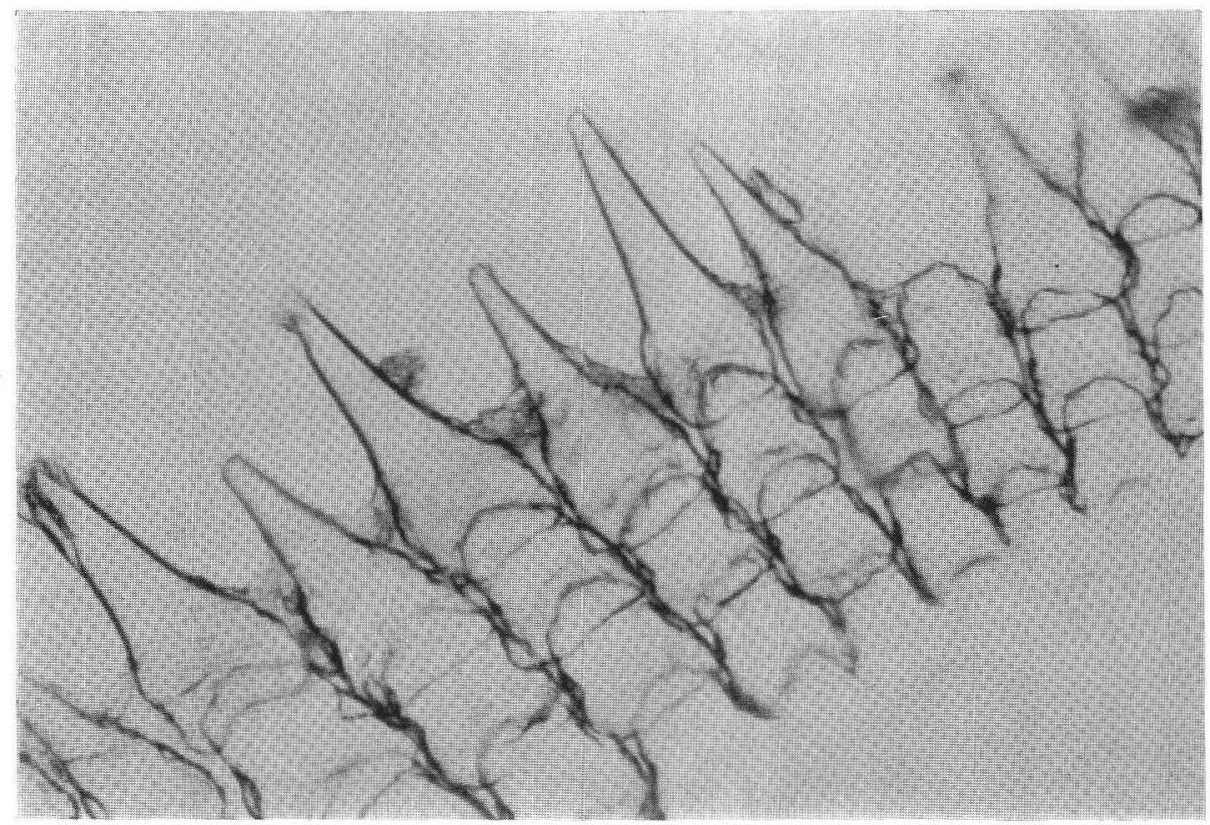

a

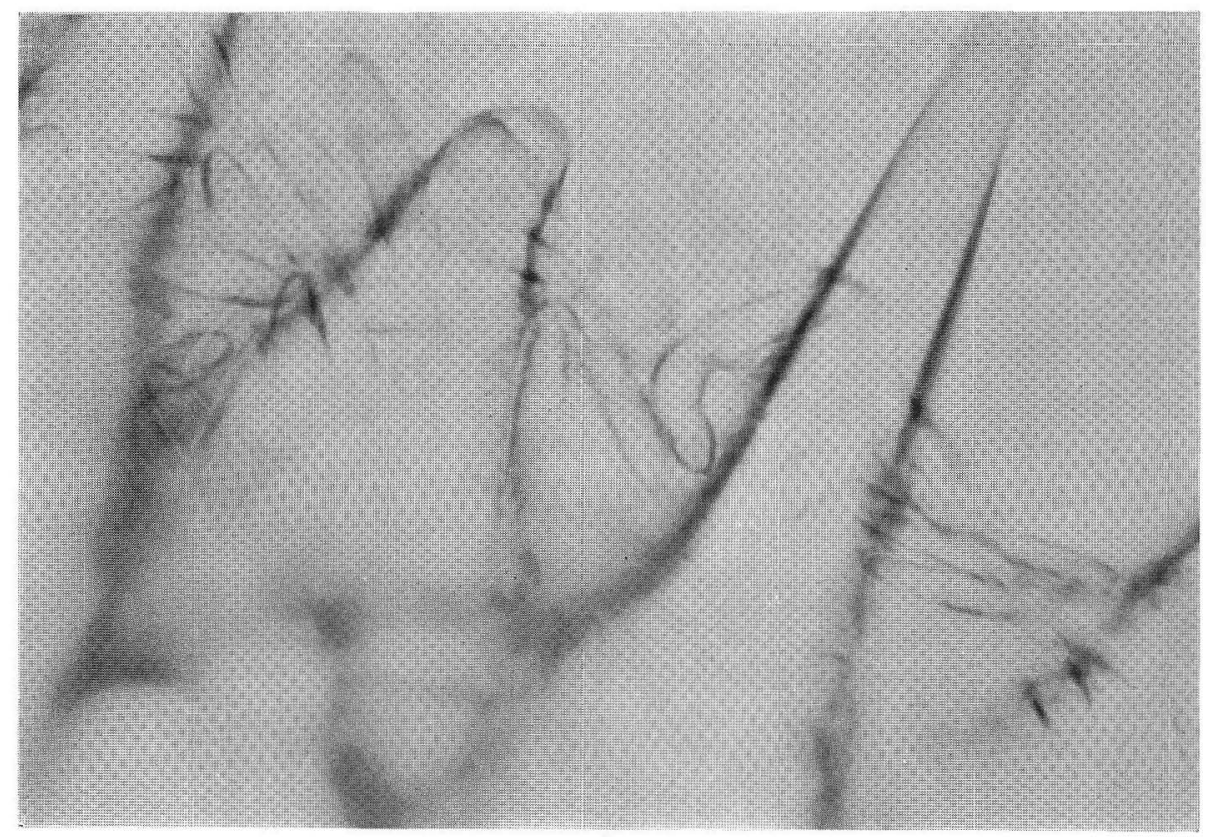

b

Fig. 5 a and b. Results of microscopical test with isolated scales. Pomacentrus' scale (b) showed a large number of discharged nematocysts attached on its surface, while, Amphiprion's scale (a) failed to do so. 


\section{Protection from Stinging by Tentacle Nematocyst:}

In judgment as to occurrence or non-occurrence of nettling by anemone's tentacle, the previous authors were dependent chiefly on visual impressions from some macroscopic observations, say, of tentacle clinging and retraction or of 'surprise' responses of fish on contact with tentacles. So I tried to use direct inspection of the discharged nematocysts under microscope as much as possible in such a judgment.

The organelles packed closely in the tentacle surfaces of Parasicyonis were identified according to WeILL's classification system as representing spirocysts and basitrichous isorhiza nematocysts (Fig. 4). They were, in size, $25.5 \mu \mathrm{m} \times 3.9 \mu \mathrm{m}$ and $22.0 \mu \mathrm{m} \times 5.0$ $\mu \mathrm{m}$, respectively. The discharging tests to be reported below concerns both of them without distinguishment. Preliminary observations with tentacles, attached to, as well as isolated by cutting from, the anemone body, indicated discharge response toward several kinds of chemicals, contact of glass rod or forceps, irrespective of whether the tentacle belonged to an acclimated anemone or not.

A series of tests as to stinging on the contact of fish were performed by pushing the fish body with a nylon dipnet lightly on to the fully expanded tentacles of a Parasicyonis several times and then releasing back to the original aquarium. In such a test there was a marked difference observed between Amphiprion and other fishes. The latter fishes including Pomacentrus coelestis, Chasmichthys dolichognathus gulosus (a goby), Navodon modestus (a puffer) suffered lethal or nearly lethal injuries from the stinging, whereas Amphiprion, whether acclimated or unacclimated, showed no change at all. Microscopical inspection of scales removed from the portion of skin that was subjected to the contact with tentacles showed a large number of discharged nematocysts attached, while these from Amphiprion always failed to do so (Fig. 5a and b). Furthermore, Amphiprion treated like this was found already in a state of established association when they were allowed to swim in the testing aquarium of anemone. Thus, the process of association could be accelerated artificially and safely by a sudden contact exerted forcibly as already mentioned. The fish appeared rapidly to attain a state of 'learning' by being given the reward without any punishment. A similar effect of acceleration could also be obtained by confining both animals in a narrow container.

That such a protection was not effective non-specifically toward any species of anemones was shown by the observation of an $A$. percula, which was pushed close to tentacles of an anemone of unidentified species and died from injuries on the next day.

The above results suggested a pre-existent capacity in Amphiprion of self-protection from stinging. So, further series of tests were performed with isolated scales by bringing them in contact gently with a tentacle of Parasicyonis. The results of microscopical inspection of scales treated like this, taken from Amphiprion, acclimated and unacclimated, and also from non-Amphiprion, are shown in Table 2. Marked difference in the figures between Amphiprion and their pomacentrid relative, as well as absence of any noticeable difference between acclimated and unacclimated state 
Table 2. Stinging response of tentacles of Parasicyonis actinostoloides to contact of isolated scale. Number of stung scales in percentage of the total count (mean \pm S.E.). T-test were made.

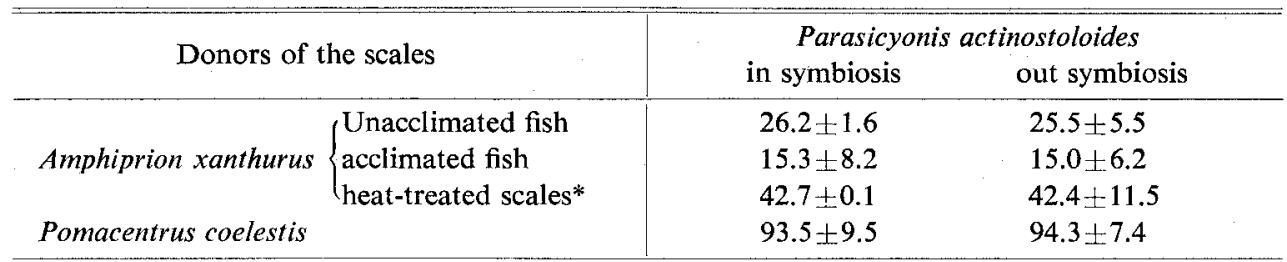

* Unacclimated fish and acclimated fish were used without distinction.

indicate that the protective capacity is on the part of fish's body surfaces rather than on the part of anemone, and that such a capacity is pre-existent to the 'acclimation', i.e., innate to the species of fish. Scales taken from the region of body surface that had been made contact with tentacles in the natural course of acclimation also showed a value as low as the control scale from another region.

Heat pre-treatment of the isolated scales of Amphiprion increased these figures of percentage of stung scales from around $20 \%$ up to $45 \%$. This may confirm the statement by DAVENPORT that the 'protective substance' is heat labile. A preliminary test of acetone pre-treatment of the scales showed no change in the protective capacity.

\section{Effects of the Presence of Anemone Fish on the Anemone:}

In the course of acclimation, there are changes also in the behavior of the anemone, as stated by previous authors. The tentacles seem to become less reactive to the contact of fish. BLösch presented some experimental results indicating the process of sensory adaptation of anemone's tentacle to mechanical contact of a piece of paper. The present author repeated BLösch's experiments in a somewhat modified forms but failed to confirm the process of such a sensory adaptation. It remains the question that filter paper $(\phi=5 \mathrm{~mm})$ used by this test was efficient stimulation to anemone's tentacle. The 'reaction' time of a tentacle in situ toward the contact of a piece of filter paper did not show any consistent with repetition. Instead, there was found fortuitously a rather marked tendency of recurrence of extraordinarily long 'reaction' time inserted into a series of shorter ones (Fig. 6). This suggested that all this recording reflects a spontaneous retractile activity of tentacle rather than an actual reaction to the contact stimulus. This suggestion turned out as reality when any one tentacle of anemone was observed continuously without touching for any such spontaneous retraction, and the time record was taken of the same, as shown in Fig. 7. The activity appeared to take place in isolated groups of several retractions, between which groups long intervals (up to $1000 \mathrm{sec}$. or more) were inserted, and such long intervals were to be supposed to correspond to the extraordinarily long 'reaction times' recorded in Fig. 6.

A further finding was that of an influence of the fish in association exerted on such a spontaneous semi-rhythm of the anemone's tentacles. One of the recordings is 


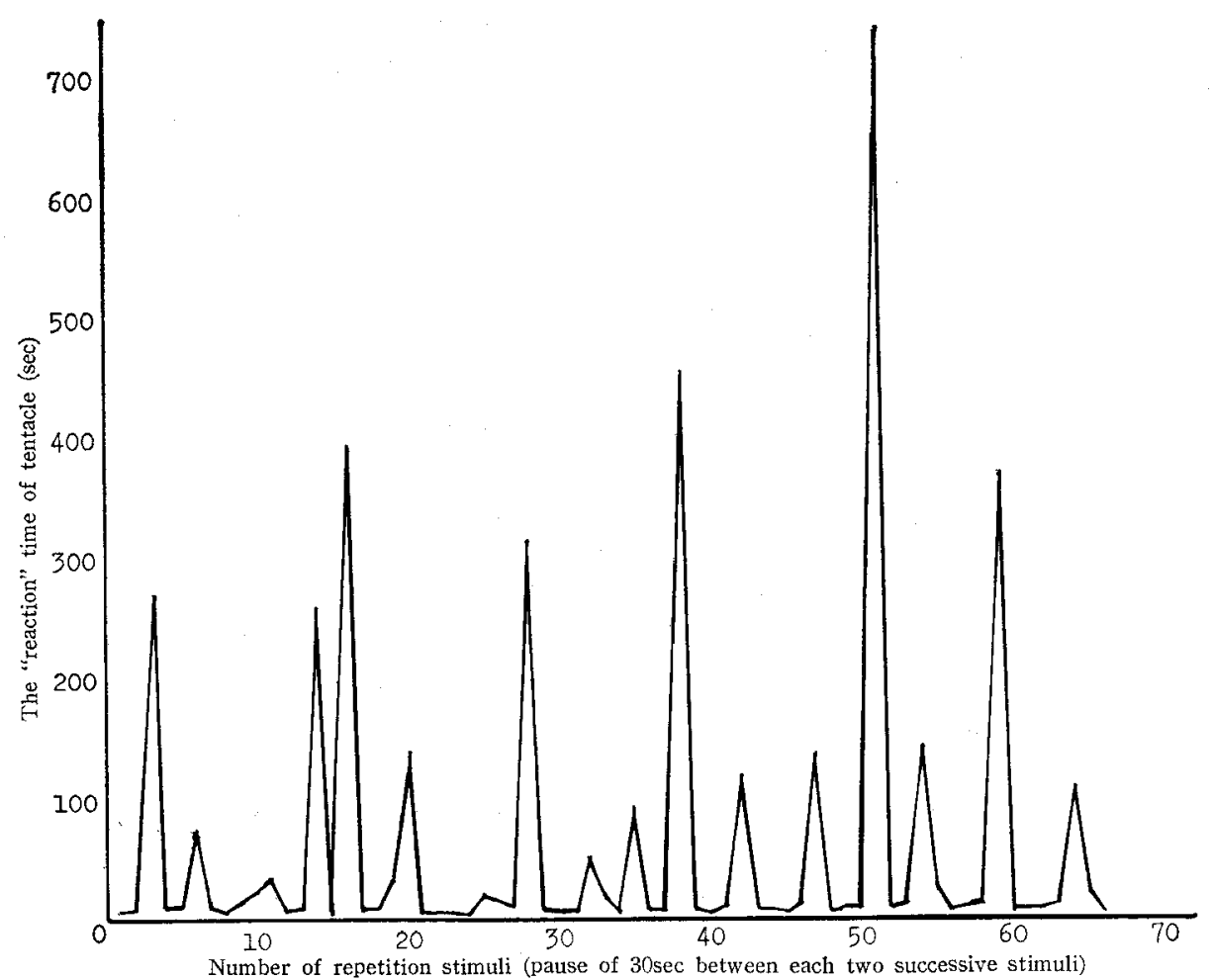

Fig. 6. 'Reaction time' toward repeated 'stimulating' tests: contact of a piece of filter paper $(\dot{\phi}=5$ $\mathrm{mm}$ ) on a tentacle in Parasicyonis (water temp. $23.0^{\circ} \mathrm{C}$ ).
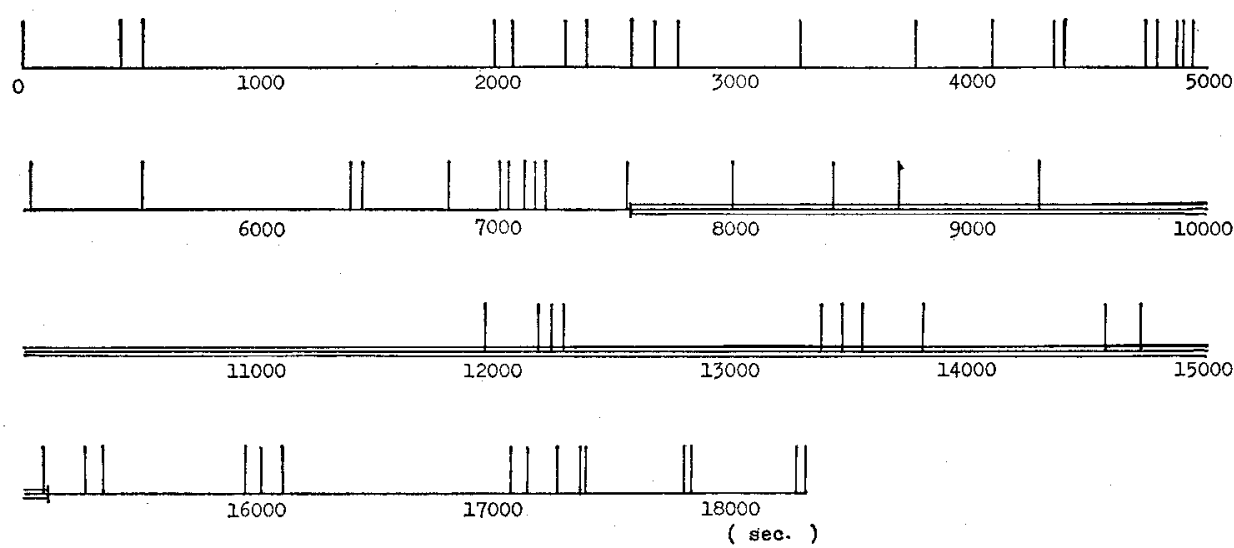

Fig. 7. Effect of presence of Amphiprion xanthurus on the spontaneous activity of one selected tentacle in Parasicyonis actinostoboides (water temp. $20.2^{\circ} \mathrm{C}$ ). Vertical bars represent each a single contraction of the tentacle. $\square$ : period of presence of Amphiprion. 
shown also in Fig. 7. As will be apparent from it, the average periodicity of spontaneous tentacle reaction was decreased rather markedly by the presence of an acclimatized fish.

This effect is to be distinguished from an effect of sensory adaptation of tentacles toward tactile stimulation, but is better to be interpreted as some specific effect of the presence of fish exerted on the whole neuromuscular pattern of activities of anemone. What is the active principle in this effect remains un known, but it is likely that a rhythmic tactile stimulation given by the see-saw movement of the fish's body is responsible for this effect. Indeed, the general impression from the sight of the couple in this social behavior reminds the hermit crab, which is reported by Ross and SuTTON (1970) to stimulate his partner anemone, Calliactis, with rhythmic tapping to a state of relaxation and pedal detachment.

A nursing or caressing effect exerted by attending anemone fish to its anemone host was already suggested by earlier authors including GOHAR and VERWEY, though DAVENPORT and Ross seemed to regard that massage effect as a mere incidental effect of the fish's own acclimatizing movement. It must be reminded here, however, that even an incidental effect can have an adaptive significance provided it takes place with an enough high probability. Indeed it may be an impression possessed by many Amphiprion keepers that their partner anemone improves his health noticeably when it is together with the symbiont fish. The sign of such an improved health is general relaxation and expansion of the anemone body. It may well be that the effect in question represents an item of 'benefit' on the part of host in the present symbiosis, beside the fish's feeding of the host, which also has been rejected by OKUNO and AOKI (1959) as a merely 'incidental' effect of a selfish habit of the fish.

\section{Discussion}

If the protection of the anemone fish against stinging is a pre-existent property of the individuals ${ }^{2)}$ and not induced first by the process of acclimation, it may be quite a natural response of a biologist to ask the question of 'why that cautious behavior of the fish?' The answer to that question will be: 'because the fish himself doesn't know if that anemone belongs to a dangerous or friendly species'. It has already been reported frequently that pomacentrid fish in general has the habit of seeking for a darker and cozy hollow or shelter in the water. While the same habit is shared by the genus Amphiprion, they are found to behave with as much cautiousness in approach to such a favorite place as in approach to a real living anemone. It seems that Amphiprion possesses a poor capacity of visual discrimination. If so, their habit of testing cautiously the target must have an adaptive value, for they can find safely the correct

2) In this connection it may be pointed out that DAVENPORT and NORRIS(1958) reported the protective capacity already furnished in the eggs of Amphiprion in contrast to the other fish's eggs. 
partner only through this process of trial-and-error learning. They are irresponsible if their human observers are deceived by their acts to be lead to a misunderstanding, which could be avoided if direct microscopical inspection for stinging capsules was done.

The only issue left for a further discussion in this connection may be the phenomenon of tentacle clinging which was reported by DAVENPORT, MARISCAL and other workers to take place prior to the establishment of acclimation. It might be interesting to see with Stoichactis anemone whether the clinging of the tentacle to the fish on contact is due to discharge of spirocysts rather than true nematocysts, which is somehow suppressed after the acclimation.

The behavior on the part of the host anemone is also deceiving, if the anemone merely responds directly and physiologically to stimulation by the fish. The slow procedure of approach on the part of fish might make this direct response also correspondingly slow in setting in, thus giving the impression of an adaptative process intervening.

To put it briefly, the present writer's suggestion here is the likeliness that the symbiosis between anemone fish and anemone is based on built-in (maybe innate) properties of both partner animals, but that the necessity of self-learning process on the part of fish to be involved makes the establishment of the association a slow process at least in a natural setup in field.

\section{Acknowledgements}

I am greatly indebted to Dr. T. M. YANAGITA, Ochanomizu University, for many helpful discussions and suggestions in preparation of this paper. Much thanks are also due to the staff of the Shimoda Marine Biological Laboratory for kind help in collection of the anemone material.

\section{REFERENCES}

BLösch, M. 1961. Was ist die Grundlage der Korallenfisch-symbiose: Schutzstoff oder Schutzverhalten? Naturwiss. $48(9): 387$.

BLÖsCH, M. 1965. Untersuchungen über das Zusammenleben von Korallenfischen (Amphiprion) mit Seeanemonen. Inaugural-Dissertation, Eberhard-Karls-Universität zu Tübingen.

DavenPort, D. and Norris, K. S. 1958. Observations on the symbiosis of the sea anemone Stoichactis and the pomacentrid fish Amphiprion percula. Biol. Bull. 115 (3): 397-410.

Davenport, D. 1966. Cnidarian symbioses and the experimental analysis of behavior. In W. J. ReEs (ed.), 'The Cnidaria and their Evolution', pp. 361-372, London: Academic Press.

GoHAR, H. A. F. 1948. Commensalism between fish and anemone (with a description of the eggs of Amphiprion bicinctus RüPpelL). Fouad I. Univ. Publ. Mar. Biol. Sta. Ghardaqa (Red Sea) 6: $35-44$.

Mariscal, R. N. 1969. The protection of the anemone fish, Amphiprion xanthurus, from the sea anemone, Stoichactis kenti. Experientia. 25 (10): 1114.

MARISCAL, R. N. 1970a. An exprimental analysis of the protection of Amphiprion xanthurus CUvIER \& VAlENCIENNES and some other anemone fishes from sea anemones. J. Exp. Mar. Biol. Ecol. 4 (2): 134-149. 
Mariscal, R. N. 1970b. The nature of the symbiosis between Indo-Pacific anemone fishes and sea anemones. Mar. Biol. 6 (1): 58-65.

Mariscal, R. N. 1970c. A field and laboratory study of the symbiotic behavior of fishes and sea anemones from the tropical Indo-Pacific. Univ. California Publ. in Zool. 91. 33pp, and 4 plates.

OKUno, R. and AокI, T. 1959. Some observations on the symbiosis between the pomacentrid fish and the sea anemone. Dobutsuen Suizokukan Zasshi (J. of Zoos and Aquaria) 1: 8-11. (In Japanese).

Ross, D. M. and Surron, L. 1970. The detachment of the commensal sea anemones, Calliactis polypus and C. tricolor by mechanical and electrical stimulation. Z. vergl. Physiologie 67: 102-119.

SChLichter, D. 1968. Das Zusammenleben von Riffanemonen und Anemonenfischen. Zeits. f. Tierpsychologie. 25.

VerweY, J. 1930. Coral reef studies. I. The symbiosis between damsel-fishes and sea anemones in Batavia Bay. Treubia 12 (2-4): 305-366. (Cited from DAVEnPoRT, 1958).

Weill, R. 1934. Contribution a l'étude des cnidaires et de leurs nématocystes. 1: 88-103.

\section{DISCUSSION}

MülleR: You mentioned the old work of Dr. Blösch but not the more recent work of Dr. SChLichter. Dr. Schlichter gave unequivocal evidence that the fish protects itself by taking up mucous smears from the anemone. This slime serves as a coat which prevents the anemone from being poisoned by its own toxins. The fish takes up the slime during the initial period of acclimation by means of its approaching behaviour. Dr. SCHLICHTER was even able to accomodate fishes which are never associated with anemones by applying slime of anemones to their skin. The difference between Amphiprion and other fishes lies in the fact, that Amphiprion does not hesitate to approach the anemones again if initially poisoned. This seems to be the whole mystery of the story.

Fukur: I am aware of the results which Dr. SCHLICHTER reported in 1968. There may be such an effect of acquired protection as he concludes. In any way, however, my finding is that the protection of anemone fish against stinging is pre-existent to acclimation, so that a development or reinforcement of such a capacity, if any, may be supposed to be of secondary importance. 